\title{
Characteristics and dynamics of crescentic bar events at an open, Mediterranean beach
}

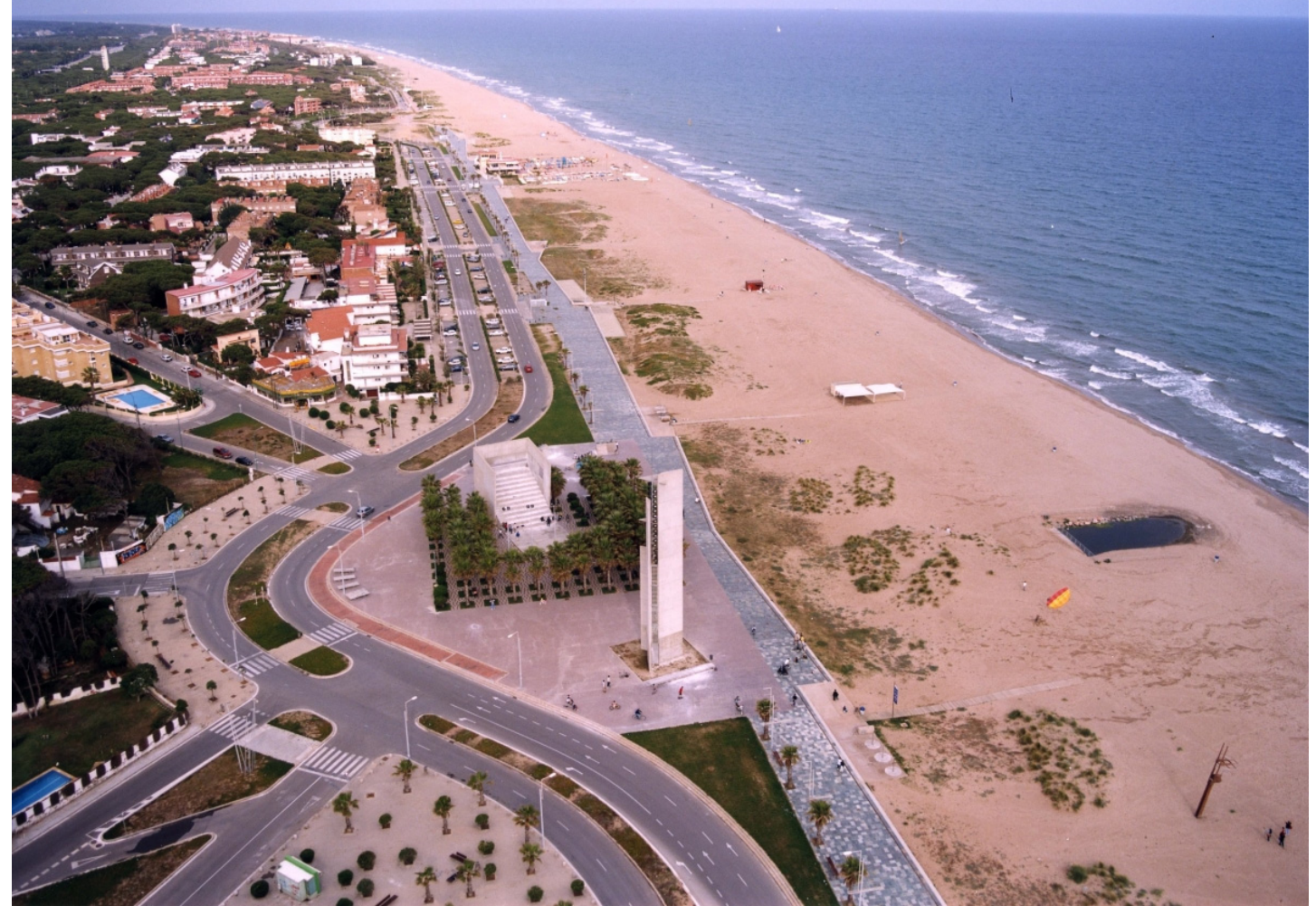

Rinse de Swart ${ }^{*}$,

Francesca Ribas ${ }^{1}$, Daniel Calvete ${ }^{1}$,

Gonzalo Simarro², Jorge Guillén²

*rinse.de.swart@upc.edu

${ }^{1}$ Coastal Morphodynamics Group, Universitat Politècnica de Catalunya, Barcelona, Spain

2Department of Marine Geosciences, Institut de Ciències del Mar (ICM-CSIC), Barcelona, Spain

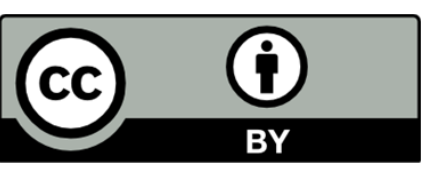

UNIVERSITAT POLITÈCNICA DE CATALUNYA BARCELONATECH morfos

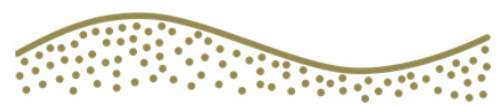

ICM

Institut

de Ciències del Mar 
$\square$ Bar observations using time-exposure camera images

- Foam pattern is a good proxy for bar position

- Shore-parallel bar $=$ alongshore uniform pattern

- Crescentic bar = alongshore variable pattern (undulating)

- Crescentic bars have been observed at various sites worldwide

- Physical processes well-studied (morphodynamic modelling)

\section{Alongshore uniform}

Crescentic

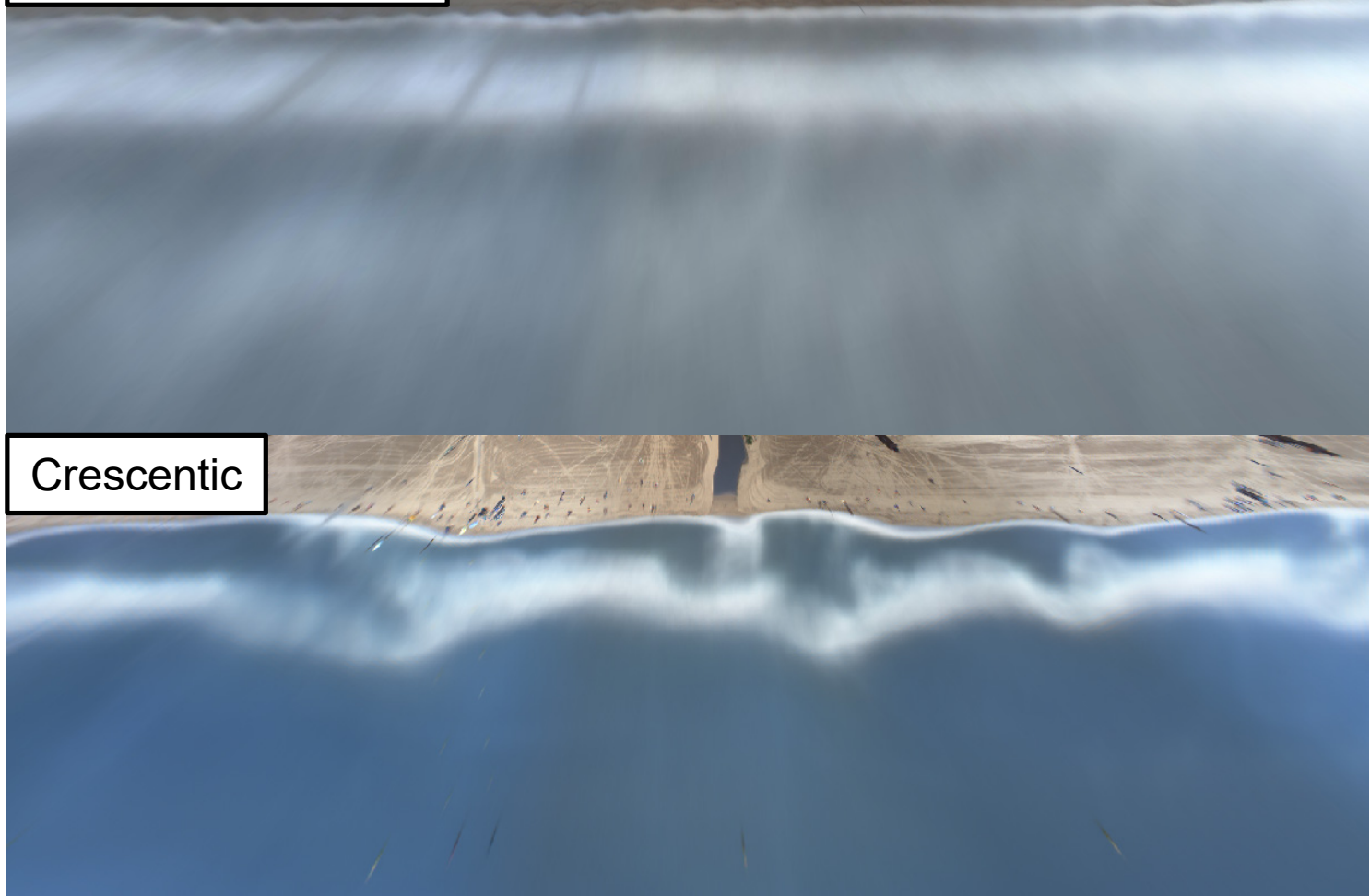


$\square$ Motivation

- No detailed description of environmental conditions during crescentic bar formation and destruction

- Role of wave obliquity not yet clear

- Lack of observations in fetch-limited conditions with low tides

$\square$ Aim

- Increase our knowledge on the dynamics of crescentic bars (including formation/destruction moments)

- Particularly in fetch-limited environments with very low tides

- Clarify the role of wave obliquity

$\square$ NEW

- Event approach: detect and analyse crescentic bar events

- Well-validated spectral wave conditions

- Detailed analysis of environmental conditions during crescentic bar presence and formation/destruction 
Mediterranean Sea, $20 \mathrm{~km}$ southwest of Barcelona (Spain)

- Wave conditions taken from Barcelona wave buoy (68 $\mathrm{m}$ depth)

Waves propagated to $10 \mathrm{~m}$ depth in front of study site (SWAN)

- SWAN forcing*: 2D directional spectra complemented with integrated wave parameters (when 2D spectra were missing)

*Note:

An extensive description and validation of the wave propagation method used in this study can be found in the following article: De Swart, R.L., Ribas, F., Calvete, D., Kroon, A., \& Orfila, A. (2020). Optimal estimations of directional wave conditions for nearshore field studies. Continental Shelf Research, 196, 104071, https://doi.org/10.1016/j.csr.2020.104071

\section{(782

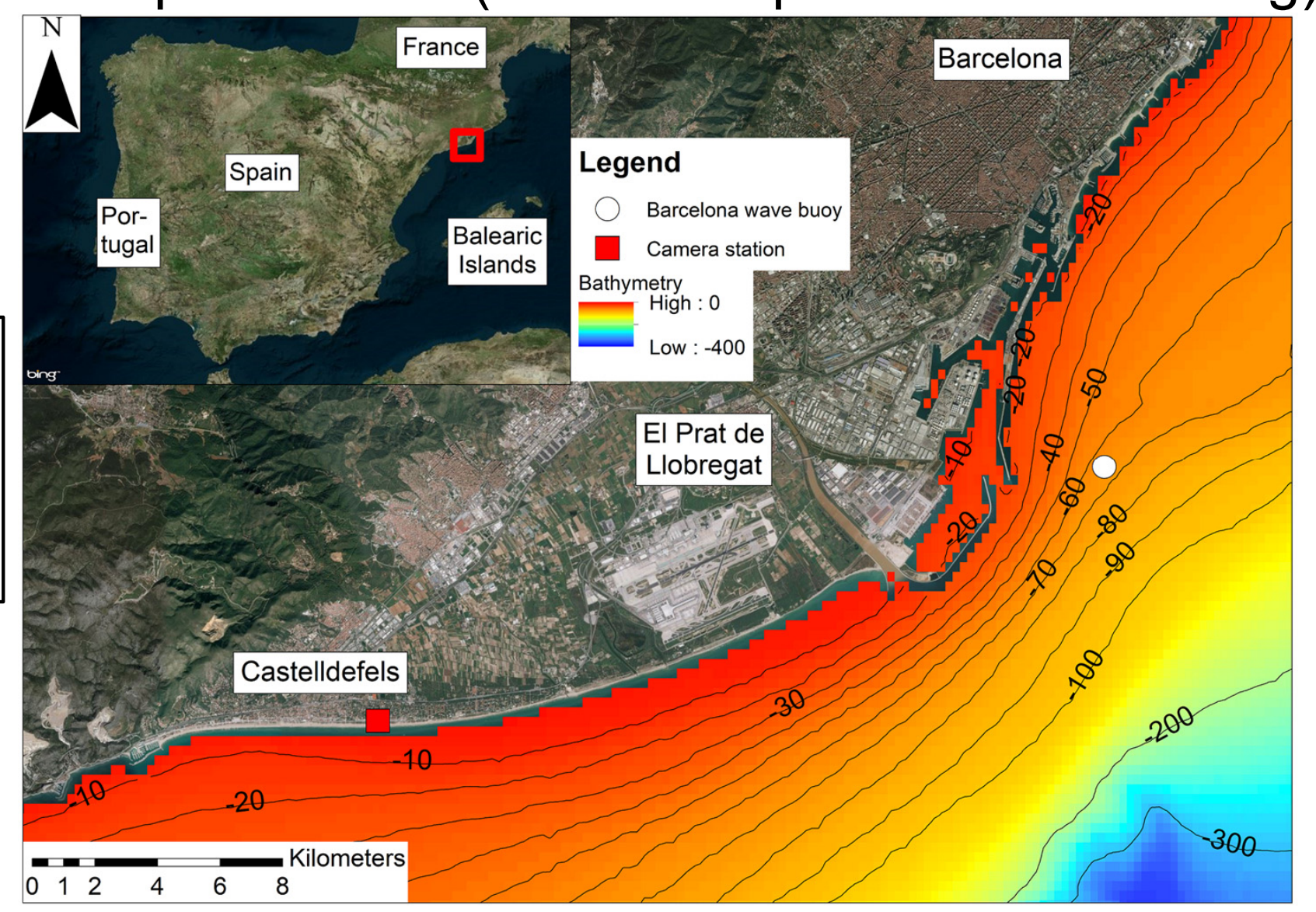


$\square$ Study site: Castelldefels beach (Plaça de les Palmeres)

- Open, dissipative beach (tidal range $\approx 10-20 \mathrm{~cm}$ )

- East-west coastline orientation

$\square$ Time-exposure images taken every hour using 10 min average - Merged in planview (1 km alongshore, $300 \mathrm{~m}$ cross-shore)

Dataset October 2010 - August 2018

- No camera data from October 2016 - January 2017

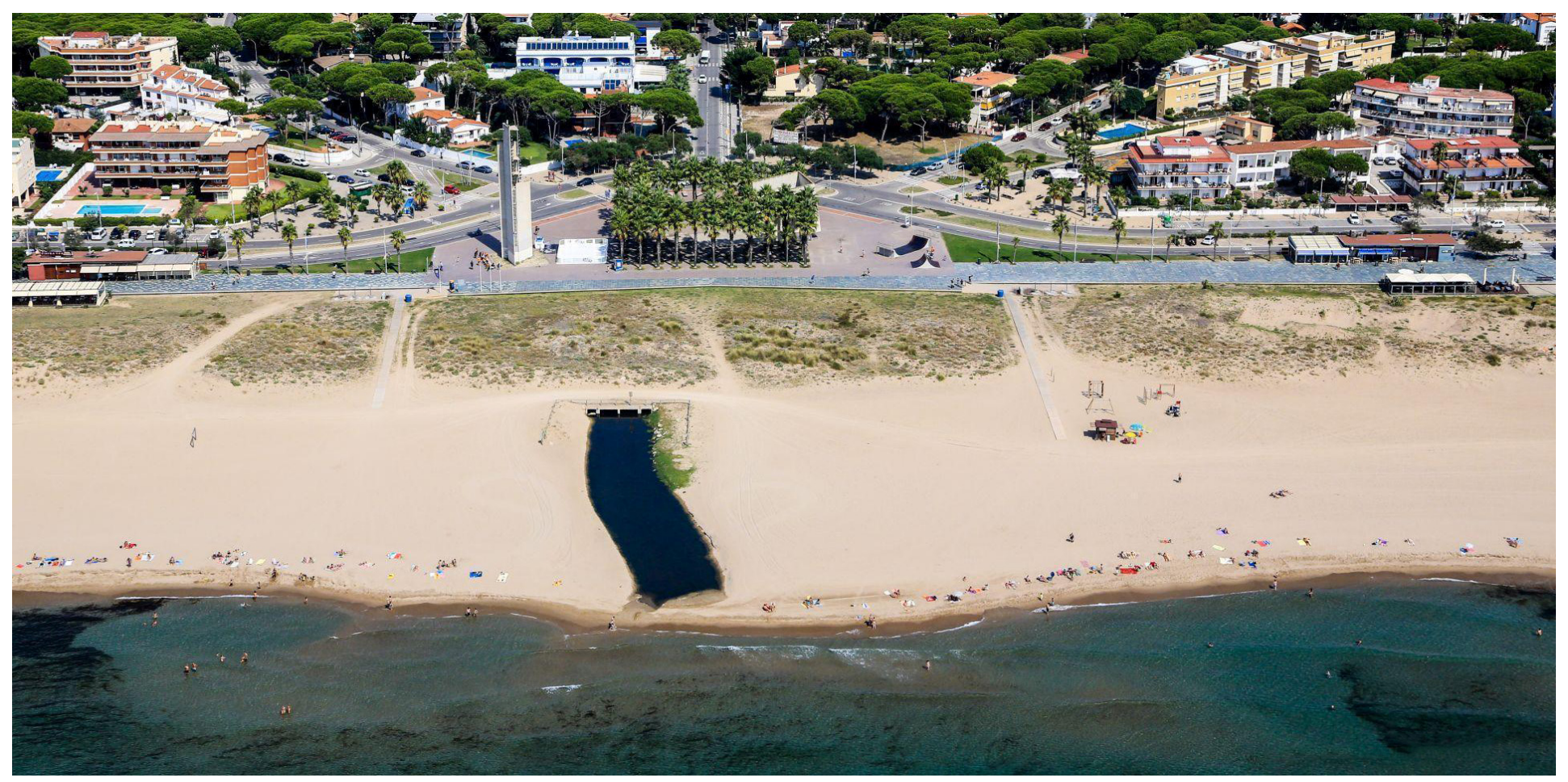


Visual analysis of images dataset

Detect crescentic bar events and formation/destruction moments 
Visual analysis of images dataset

Detect crescentic bar events and formation/destruction moments 
$\square$ Visual analysis of images dataset

Detect crescentic bar events and formation/destruction moments 
Visual analysis of images dataset

Detect crescentic bar events and formation/destruction moments 
$\square$ Quantitative analysis of planviews

*Note:

BLIM: A toolbox for the analysis of nearshore time-exposure images. See https://sourceforge.net/projects/blimtoolbox/

- Mostly 1 planview per day (foam pattern should exist)

- Track barline using BLIM* (detect max foam intensity in image)

$\square$ For each barline, find peaks and troughs in barline

$\square$ Compute several parameters per barline

- Alongshore-averaged cross-shore sandbar position,

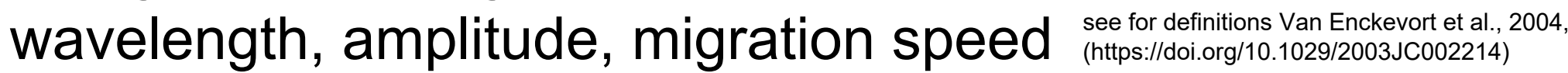




\section{$\square$ Strong variation in crescentic bar presence}

- No seasonal variability in crescentic bar occurrence

- Crescentic bars normally develop in inner bar (except 2017/2018)

- Strong correlation between crescentic bar presence and alongshore-averaged sandbar position

Figure explanation:

Time series of (from top to bottom) the number of days per month with crescentic bars $\mathrm{N}_{\text {day }}$ the alongshore-averaged sandbar position $\mathrm{B}_{\mathrm{y}}$ (shoreline around $140 \mathrm{~m}$ ), the spectral wave height $\mathrm{H}_{\mathrm{m} 0}$ and the mean wave direction with respect to the shore normal $\theta_{\text {mean }}$ (positive angles are waves from the west). The colours in the two upper panels denote the different sandbars, whereas the colours in the two lower panels denote the SWAN forcing.

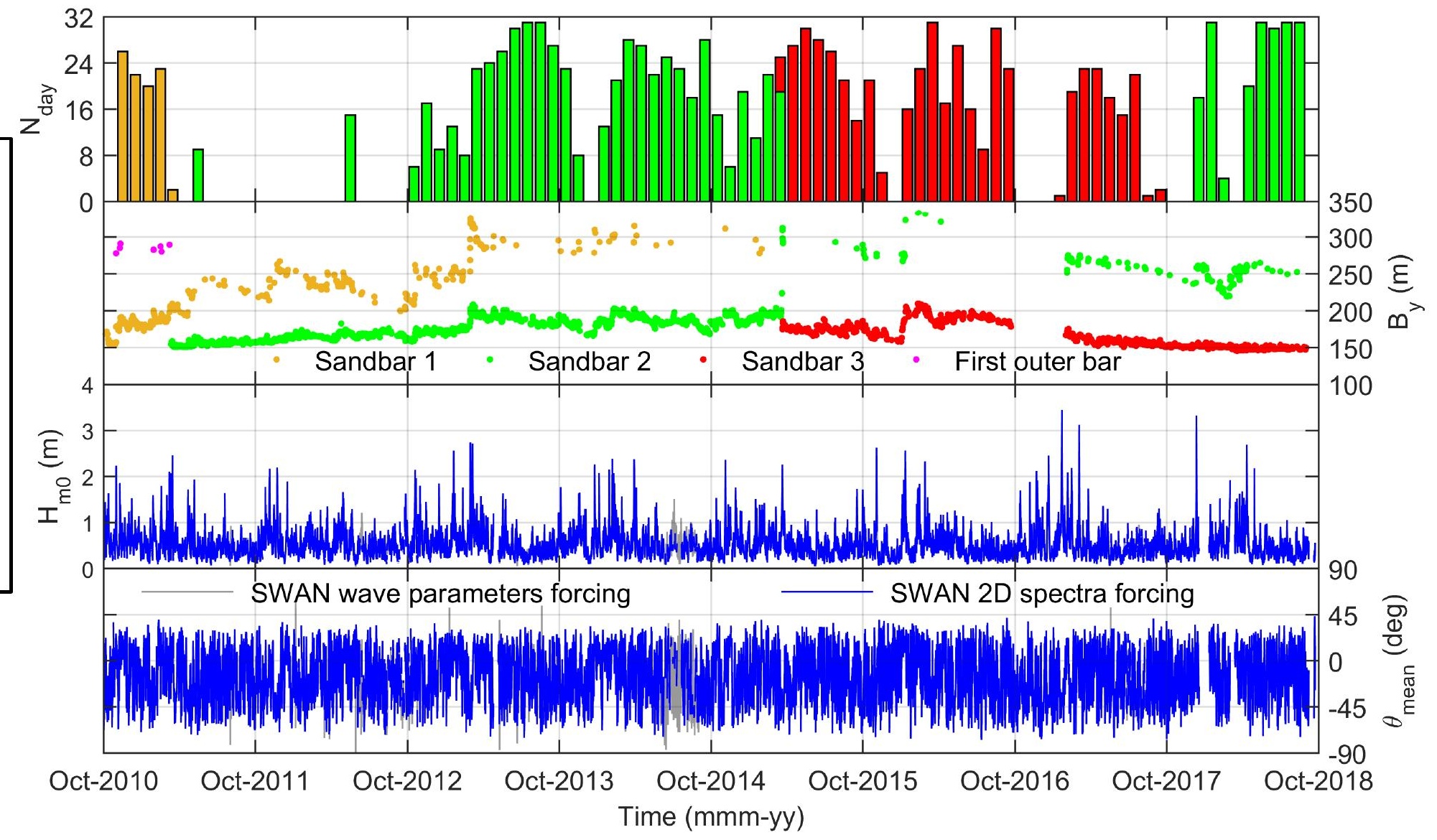


$\square$ Overview of crescentic bar events per year

- Large variability in crescentic bar occurrence per year

- Duration can vary from a few days to a few months

- Crescentic bars presence during some years for $66 \%$ of the time

\begin{tabular}{|l|l|l|l|l|l|}
\hline Year & $\begin{array}{l}\text { Number of } \\
\text { events }\end{array}$ & $\begin{array}{l}\text { Mean duration } \\
\text { (days) }\end{array}$ & $\begin{array}{l}\text { Min duration } \\
\text { (days) }\end{array}$ & $\begin{array}{l}\text { Max duration } \\
\text { (days) }\end{array}$ & $\begin{array}{l}\text { Total duration } \\
\text { (days) }\end{array}$ \\
\hline 2010 & 6 & 11 & 2 & 25 & 68 \\
\hline 2011 & 4 & 9 & 3 & 13 & 34 \\
\hline 2012 & 7 & 7 & 1 & 15 & 47 \\
\hline 2013 & 14 & 17 & 1 & 117 & 244 \\
\hline 2014 & 14 & 18 & 2 & 47 & 245 \\
\hline 2015 & 15 & 15 & 3 & 41 & 230 \\
\hline 2016 & 9 & 21 & 2 & 49 & 192 \\
\hline 2017 & 19 & 9 & 2 & 53 & 177 \\
\hline 2018 & 1 & 143 & 143 & 143 & 143 \\
\hline
\end{tabular}




\section{$\square$ Time-stack entire study period}

- Shore-parallel/crescentic bars

- Bar arrestment/bar migration

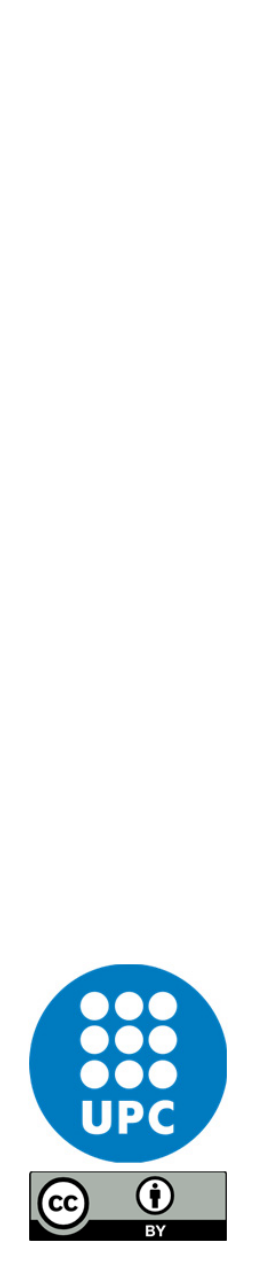

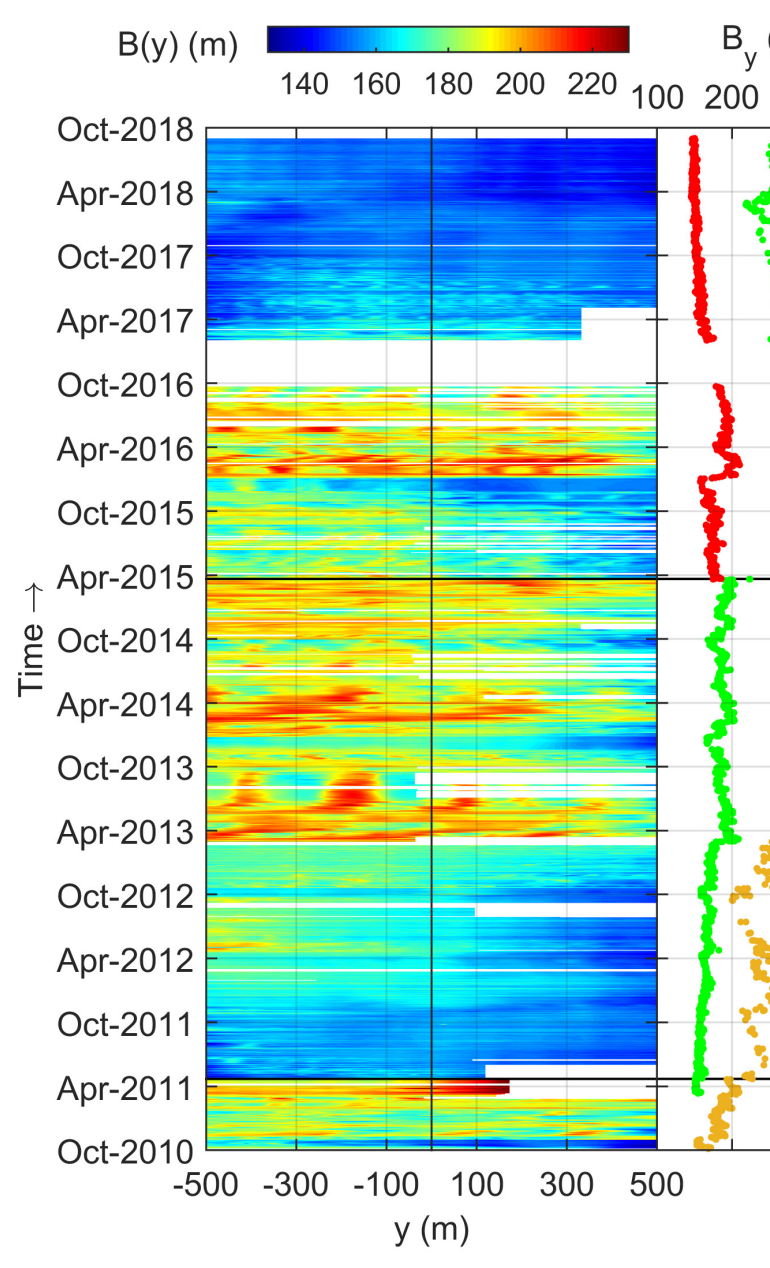

$B_{y}(m)$

400
Figure explanation:

Time series of (from left to right) the cross-shore bar crest positions $\mathrm{B}(\mathrm{y})$ at each alongshore location (shoreline located around $140 \mathrm{~m}$ ), alongshore-averaged sandbar position $\mathrm{B}_{\mathrm{y}}$, alongshore-averaged wavelength $\mathrm{L}_{\mathrm{y}}$, alongshore-averaged amplitude $A_{y}$, average migration speed $C_{y}$ (positive for eastward migration), offshore ( $10 \mathrm{~m}$ depth) spectral wave height $\mathrm{H}_{\mathrm{m} 0}$, mean period $\mathrm{T}_{\mathrm{m} 02}$ and mean wave direction with respect to the shore normal $\theta_{\text {mean }}$ (positive for waves from the west). Analogous to the previous slide, the colours in panels 2-5 denote the different sandbars and the colours in panels 6-8 denote the SWAN forcing. The horizontal black lines indicate when a new sandbar starts to be plotted in panel 1.

$\mathrm{A}_{\mathrm{y}}(\mathrm{m}) \quad \mathrm{H}_{\mathrm{mo}}(\mathrm{m}) \quad \theta_{\text {mean }}(\mathrm{deg})$ $-90-45 \quad 0 \quad 4590$ $\begin{array}{lllll}0 & 1 & 2 & 3 & 4\end{array}$

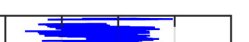


$\square$ Wave conditions during crescentic bar events

- Mainly low-energetic wave conditions with variable wave angles during crescentic bar formation and crescentic bar events

- Crescentic bar destruction during intermediate energy waves

- Clear link between destruction and angle of incidence

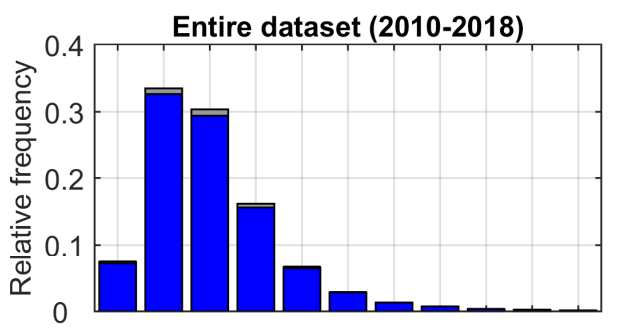

0.10 .30 .50 .70 .91 .11 .31 .51 .71 .92 .1 $\mathrm{H}_{\mathrm{mo}}(\mathrm{m})$
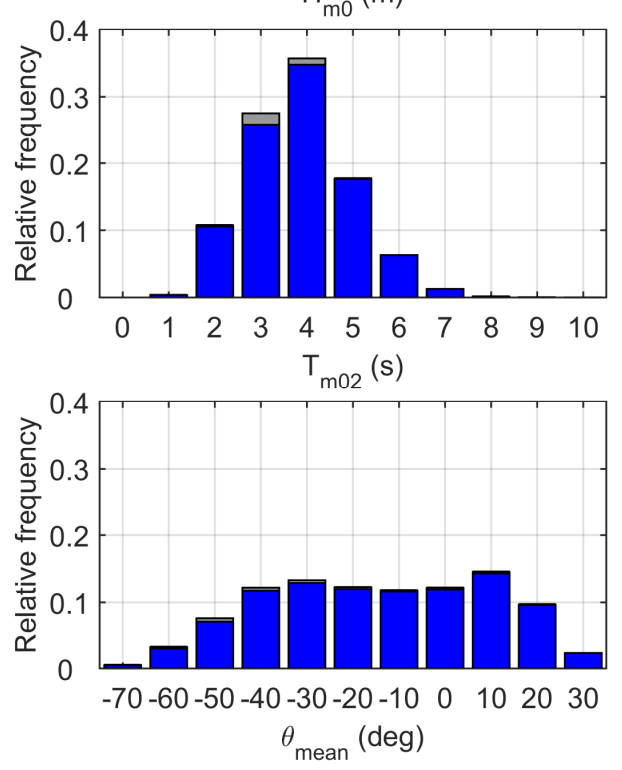

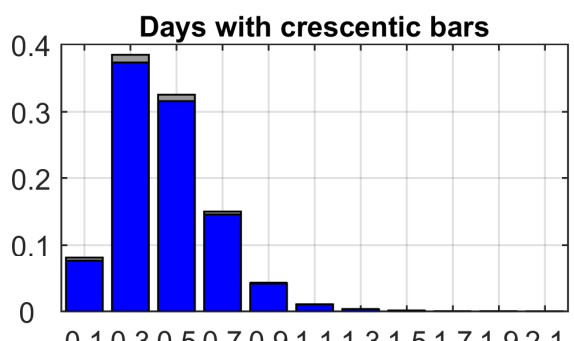

0.10 .30 .50 .70 .91 .11 .31 .51 .71 .92 .1 $\mathrm{H}_{\mathrm{mo}}(\mathrm{m})$

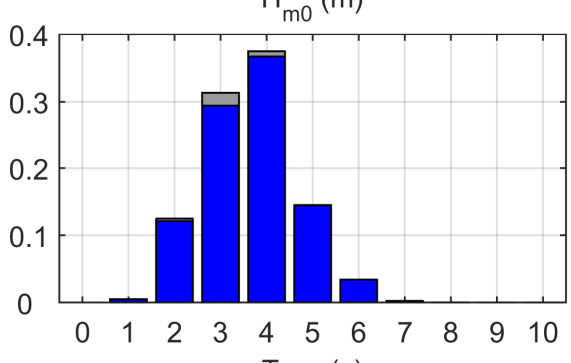

$\mathrm{T}_{\mathrm{m02}}(\mathrm{s})$

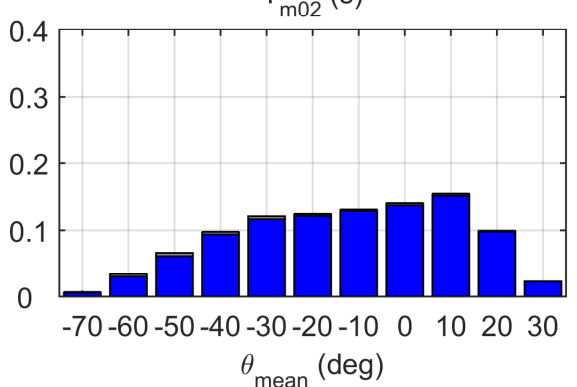

Formation moments

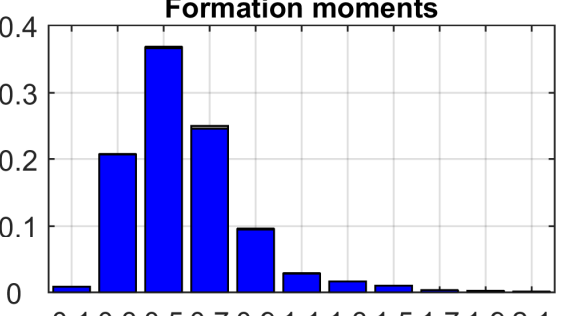

0.10 .30 .50 .70 .91 .11 .31 .51 .71 .92 .1 $\mathrm{H}_{\mathrm{m} 0}(\mathrm{~m})$
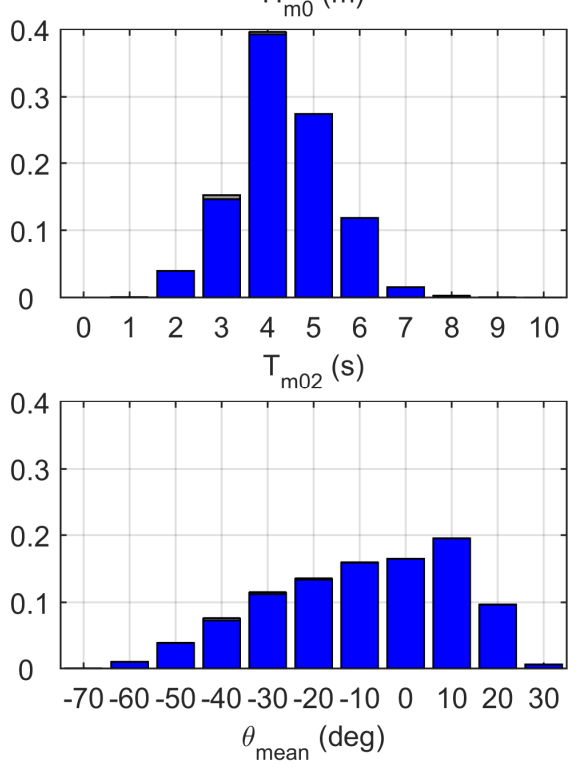

Destruction moments

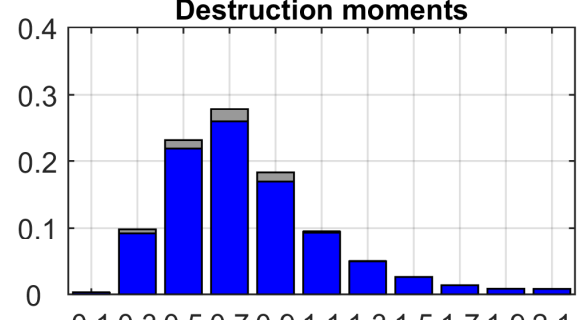

0.10 .30 .50 .70 .91 .11 .31 .51 .71 .92 .1 $\mathrm{H}_{\mathrm{m} 0}(\mathrm{~m})$

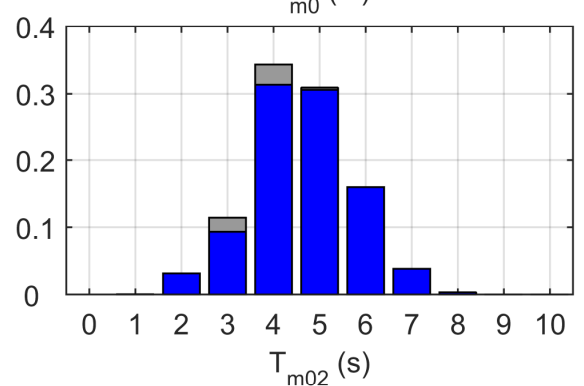

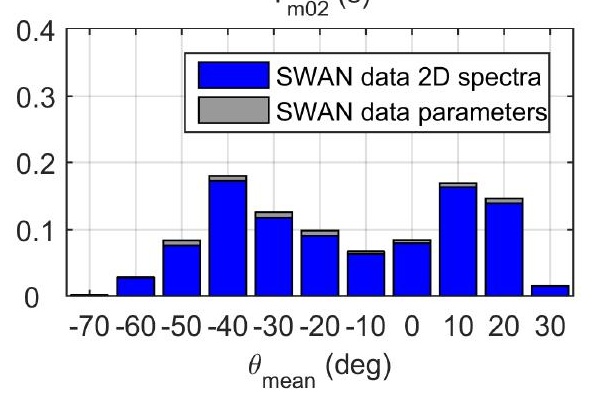


- Crescentic bars at Castelldefels compared to other studied sites

- Smaller wavelength, amplitude and migration speed

- Probable cause: less energetic wave conditions

$\square$ Crescentic bar formation

- Importance of cross-shore bar position (bar too close to shore: no crescentic bar formation)

- Large range of incidence angles

- Difficult identifying exact formation moment in images

$\square$ Crescentic bar destruction

- Intermediate-energy wave conditions

- Dominance of oblique wave angles

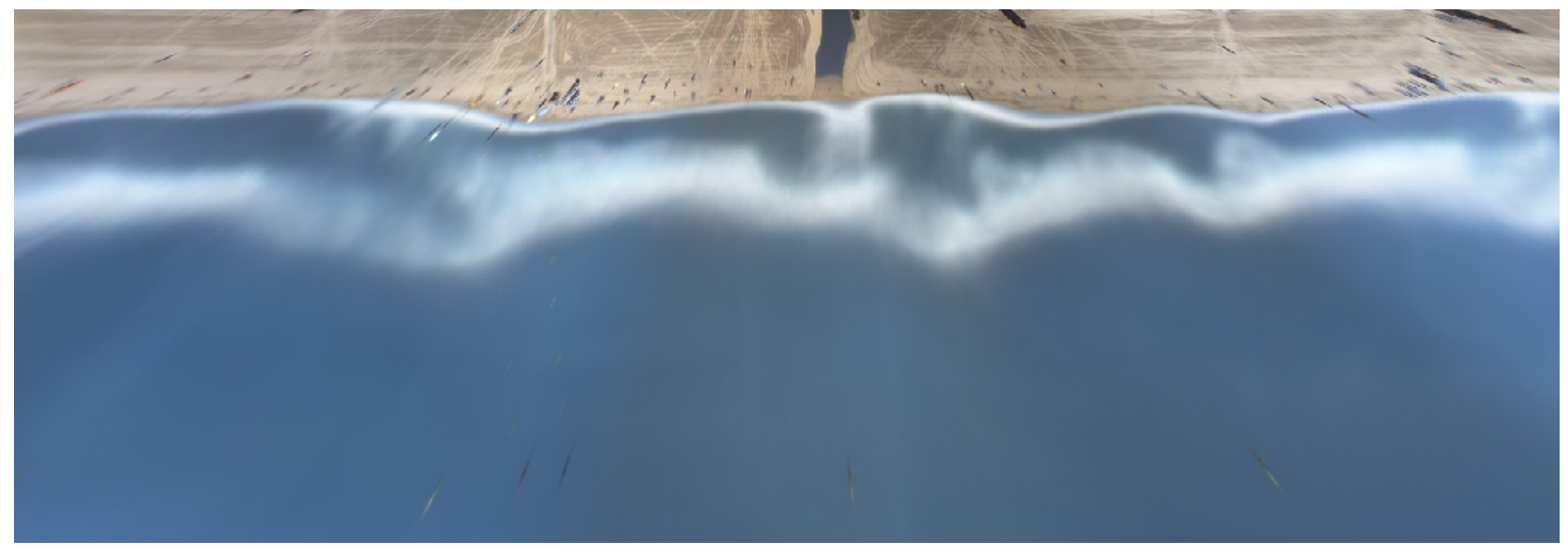


Large variability in crescentic bar occurrence

- Many events in 2010/2013/2014/2015/2016

- Very few events in 2011/2012/2018

- Smaller sizes and slower dynamics compared to other sites

$\square$ Strong link between crescentic bar presence and barline-shoreline distance

- No crescentic bar formation when bar is too close to shore

$\square$ Crescentic bar development

- Low-energy conditions

- Oblique and shore-normal waves

- Crescentic bar destruction

- Intermediate-energy conditions

- Oblique wave angles dominate

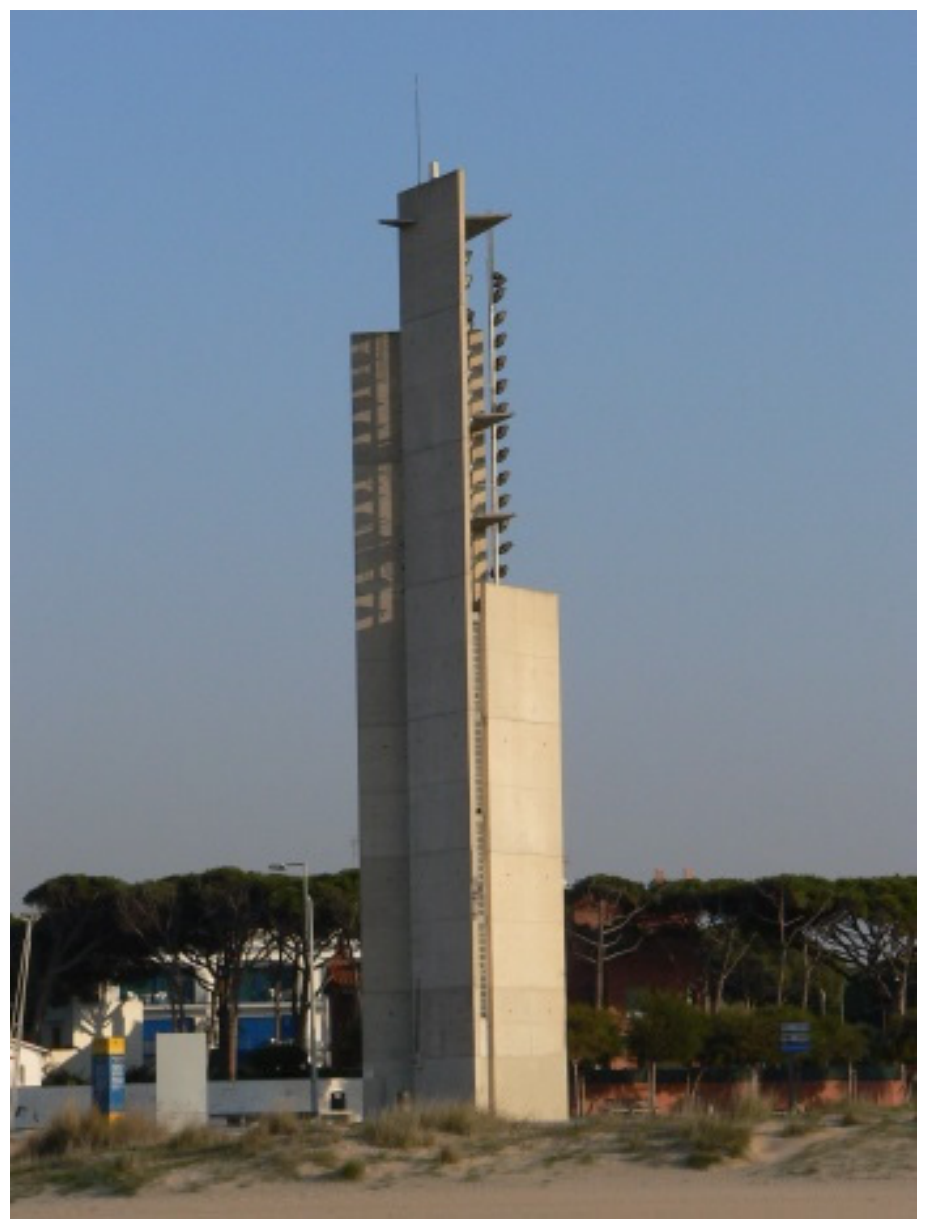

